\title{
COMPARISON OF VIRTUAL FIELDS METHOD, PARALLEL NETWORK MATERIAL MODEL AND FINITE ELEMENT UPDATING FOR MATERIAL PARAMETER DETERMINATION
}

\author{
Florian Dirisamer*, Umut D. Çakmak, Imre Kállai, Martín Machado, \\ ZOLTÁN MAJOR \\ Institute of Polymer Product Engineering, Johannes Kepler University Linz, Altenbergstrasse 69, 4040 Linz, \\ Austria \\ * corresponding author: Florian.Dirisamer@jku.at
}

\begin{abstract}
Extracting material parameters from test specimens is very intensive in terms of cost and time, especially for viscoelastic material models, where the parameters are dependent of time (frequency), temperature and environmental conditions. Therefore, three different methods for extracting these parameters were tested. Firstly, digital image correlation combined with virtual fields method, secondly, a parallel network material model and thirdly, finite element updating. These three methods are shown and the results are compared in terms of accuracy and experimental effort.
\end{abstract}

KEYwORDS: DIC, finite element updating, parallel network model, VFM.

\section{INTRODUCTION}

Elastomers are often used as damping elements and undergo, depending on their constraints, uni- and multiaxial loadings in tension, compression and shearing [1-4]. The nonlinear inherent viscoelastic material behaviour of the EPDM Shore A 50 with a maximum elongation of several hundred percent makes it further complicated to extract material parameters for the whole range of time (frequency), temperature and environmental conditions relevant for the application [5, 6]. Therefore a large number of tests at different temperatures and loading velocities have to be performed (75 tests [7] for the standard method (STD)). To circumvent these difficulties and to extract the material parameters sufficiently, three different and well-known methods were used here for comparison purposes. The motivation is the biaxial characterization of elastomers for different applications (sealing, damping, etc.). Firstly, a combined methodology based on digital image correlation (DIC) 8 and virtual fields method (VFM) 9. In this method, a heterogeneous strain field is introduced in order to acquire more than one parameter in a single test. This leads to drastically reduced time and costs. Secondly, a parallel network material model (PNMM) with the procedure of Bergström 10. (MCalibration and PolyUMod), where a test procedure including hysteretical and relaxation behaviour at certain temperatures, velocities, as well as test conditions leading to the modeling of the viscoelastic behaviour. Thirdly, a finite element updating (FEU) procedure using the Abaqussolver [11] is utilized. Measured force-displacement signals are compared to the simulated ones and the material parameters are updated until these two signals fit sufficiently within a defined tolerance. Finally, these three methods are compared in terms of accuracy

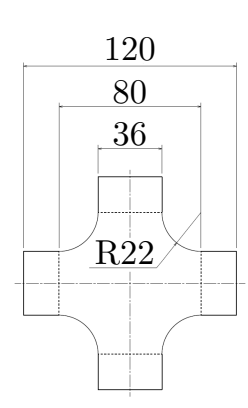

(A) . Specimen

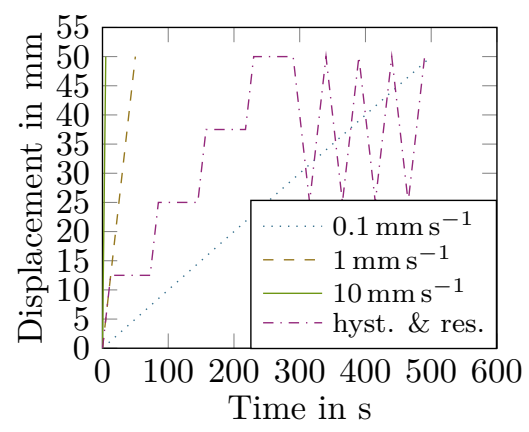

(в) . Displacement-time diagram.
FiguRE 1. Biaxial test specimen with dimensions in $\mathrm{mm}$ and displacement-time diagram for $0.1 \mathrm{~mm} \mathrm{~s}^{-1}$, $1 \mathrm{~mm} \mathrm{~s}^{-1}, 10 \mathrm{~mm} \mathrm{~s}^{-1}$ and with the procedure including hystereses and relaxation for the experiments.

and experimental effort and the advantages as well as disadvantages are summarized for each method.

\section{Description of the Methods}

The biaxial test specimens (Figure 1A) were tested with a biaxial test frame 2 at $20^{\circ} \mathrm{C}$ in a temperature chamber (CTS GmbH, Jennersdorf, AUT), loaded by an $1.5 \mathrm{kN}$ actuator and measured with a $4.5 \mathrm{kN}$ load cell (Bose ElectroForce Systems Group, MN, USA). The optical strain measurement was performed with a DIC-camera system (Aramis, GOM mbH, Braunschweig, D) and a cold light source (dedocool, Dedotec USA inc., MA, USA) and a speckle pattern was manually applied to the biaxial test specimen. The further workflow for each of the three methods, DIC combined with VFM (Figure 4), PNMM with the procedure of Bergström (MCalibration and PolyUMod) (Figure 7) and FEU ( Figure 10), is explained in detail in the subsections 2.1 2.3 

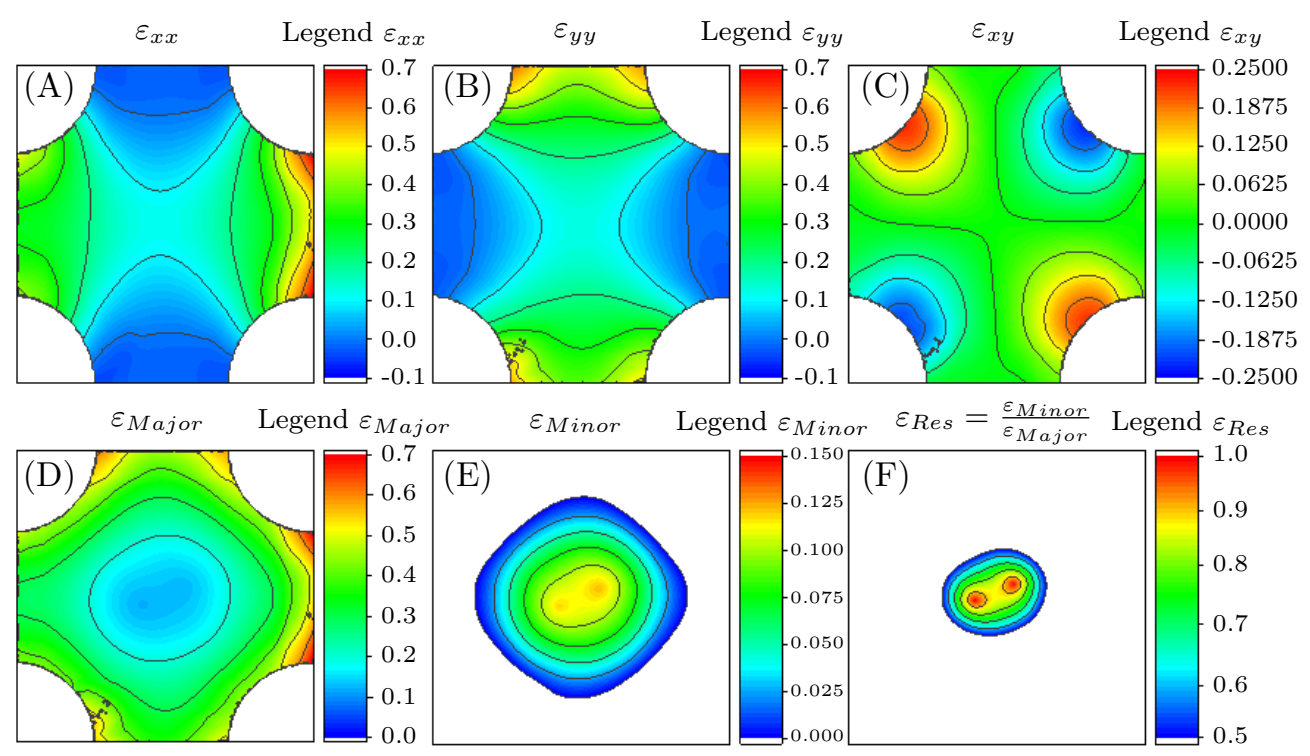

FiguRE 2. Digital image correlation results at max strains in $\varepsilon_{x x}(\mathrm{~A}), \varepsilon_{y y}(\mathrm{~B})$ and $\varepsilon_{x y}(\mathrm{C})$ and calculated results for $\varepsilon_{\text {Major }}(\mathrm{D}), \varepsilon_{\text {Minor }}(\mathrm{E})$ and $\varepsilon_{\text {Minor }} / \varepsilon_{\text {Major }}(\mathrm{F})$.

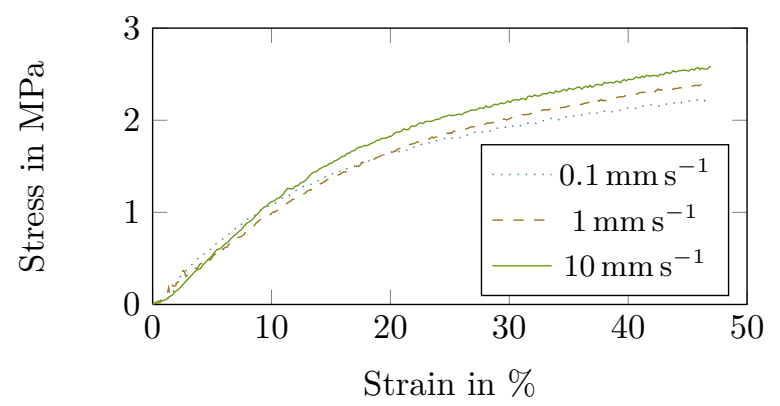

Figure 3. Stress-strain diagram for $0.1 \mathrm{~mm} \mathrm{~s}^{-1}$, $1 \mathrm{mms}^{-1}$ and $10 \mathrm{mms}^{-1}$.

\subsection{Digital image correlation (DIC) AND VIRTUAL FIELDS METHOD (VFM)}

The workflow for the VFM is shown in Figure 4 Displacement controlled tests at velocities of $0.1 \mathrm{~mm} \mathrm{~s}^{-1}$, $1 \mathrm{mms}^{-1}$ and $10 \mathrm{mms}^{-1}$ (Figure 1B) were performed with optical strain measurement and the loaddisplacement data for each of the three velocities, as well as the optical images were recorded. These image series are evaluated via DIC (ncorr, Georgia Institute of Technology, GA, USA) to generate the strain fields $\varepsilon_{x x}, \varepsilon_{y y}$ and the shear field $\varepsilon_{x y}$ (Figure 2A-C). Afterwards $\varepsilon_{\text {Major }}$ (Figure 2D) and $\varepsilon_{\text {Minor }}$ (Figure 2E) were calculated according to Equation 1.

$$
\begin{array}{r}
\varepsilon_{\text {Major/Minor }}=\frac{\varepsilon_{x x}+\varepsilon_{y y}}{2} \\
\pm \sqrt{\left(\frac{\varepsilon_{x x}+\varepsilon_{y y}}{2}\right)^{2}-\left(\varepsilon_{x x} \cdot \varepsilon_{y y}-\varepsilon_{x y}^{2}\right)}
\end{array}
$$

The equibiaxial area is the region, where $\varepsilon_{\text {Major }}$ and $\varepsilon_{\text {Minor }}$ are "equal", therefore, $\varepsilon_{\text {Res }}=\varepsilon_{\text {Major }} / \varepsilon_{\text {Minor }}$ (Figure 2F) was calculated and the equibiaxial area was extracted in the range of $\varepsilon_{R e s} \geq 0.5$. That area

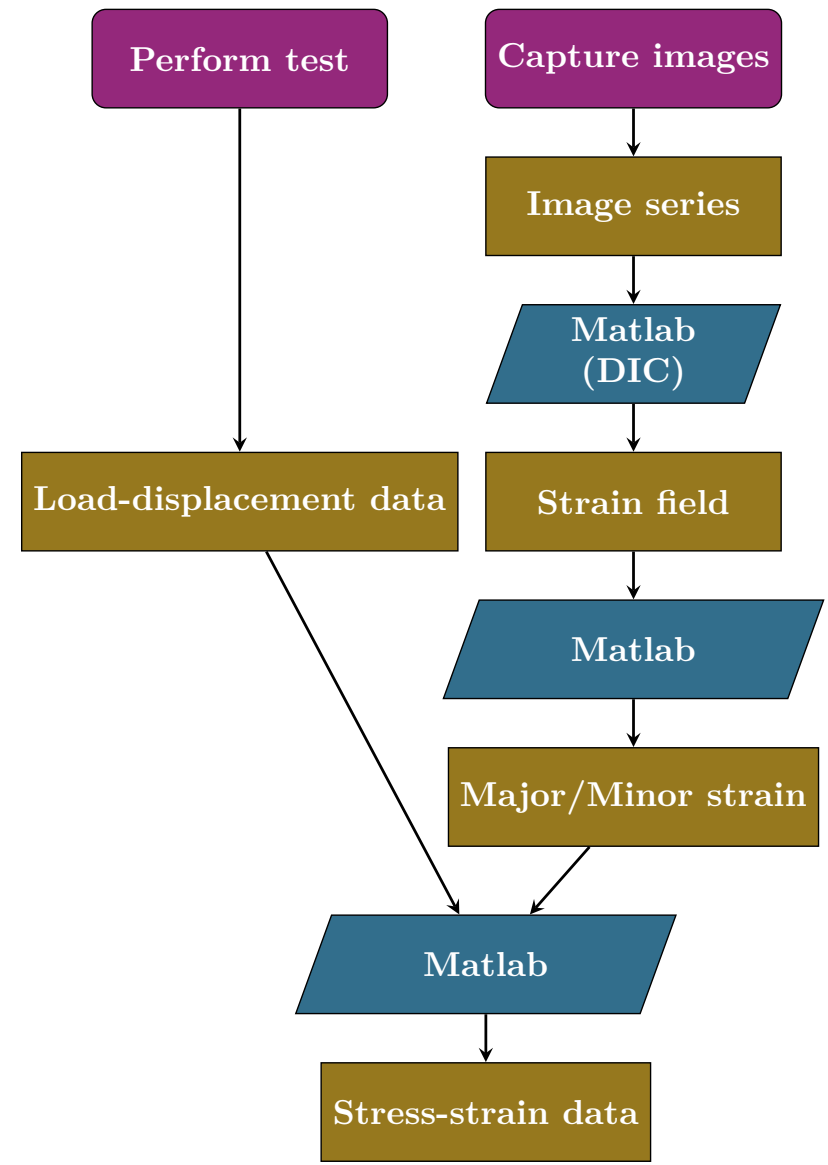

Figure 4. Workflow for the virtual fields method (VFM).

was afterwards converted to an equibiaxial diameter and the biaxiality ratio $\Phi$, the biaxial stress $\sigma$ was calculated by dividing the measured force with the equibiaxial diameter and the thickness and the strain $\varepsilon$ was calculated for each image series (Figure 3). 


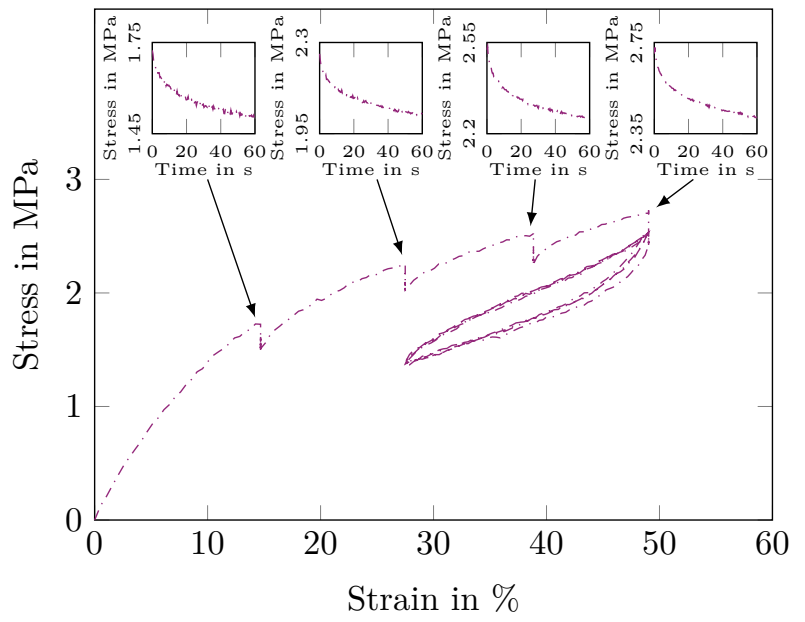

FiguRE 5. Stress-strain diagram for load with hystereses and relaxation with marked relaxation areas.

\begin{tabular}{|l|c||l|c|}
\hline Parameter & Value & Parameter & Value \\
\hline Bulk modulus & 106.59 & Lock Stretch & 4.0841 \\
\hline $\begin{array}{l}\text { Pressure depen- } \\
\text { dence of flow }\end{array}$ & -0.129 & $\begin{array}{l}\text { Temp. exp. } \\
\text { flow resistance }\end{array}$ & 0 \\
\hline $\begin{array}{l}\text { Temp. factor } \\
\text { for stiffness }\end{array}$ & 0 & $\begin{array}{l}\text { Therm. expan- } \\
\text { sion coefficient }\end{array}$ & 0 \\
\hline $\begin{array}{l}\text { Thermal expan- } \\
\text { sion ref. temp. }\end{array}$ & 293 & $\begin{array}{l}\text { Flow resistance } \\
\text { A }\end{array}$ & 0.1743 \\
\hline $\begin{array}{l}\text { Shear modulus } \\
\text { A }\end{array}$ & 7.9898 & $\begin{array}{l}\text { Stress exponen- } \\
\text { tial A }\end{array}$ & 11.499 \\
\hline $\begin{array}{l}\text { Final shear } \\
\text { modulus B }\end{array}$ & 0.9803 & $\begin{array}{l}\text { Flow resistance } \\
\text { B }\end{array}$ & 1.4018 \\
\hline $\begin{array}{l}\text { Initial shear } \\
\text { modulus B }\end{array}$ & 2.0318 & $\begin{array}{l}\text { Norm. evolu- } \\
\text { tion rate of } \mu_{B}\end{array}$ & 10.212 \\
\hline $\begin{array}{l}\text { Stress exponen- } \\
\text { tial B }\end{array}$ & 10.156 & $\begin{array}{l}\text { Relative contri- } \\
\text { bution of I2 C }\end{array}$ & $9.3 \mathrm{e}-05$ \\
\hline $\begin{array}{l}\text { Shear modulus } \\
\text { C }\end{array}$ & 1.3068 & $\mid$\begin{tabular}{l|l|} 
\\
\hline
\end{tabular}
\end{tabular}

TABle 1. Parameter table for three network material model.

\subsection{PARALlEL NETWORK MATERIAL MODEL (PNMM)}

The workflow for the PNMM is shown in Figure 7. For the procedure of Bergström (MCalibration and PolyUMod), tests which include hysteresis and relaxation domains $($ Figure 1 $\mathrm{B})$ was performed. The hysteresis and relaxation domains are necessary to model the viscoelastic behaviour with one material test at a certain temperature and velocity. As a material model, the three parallel network model [12] was chosen. It consists of:

$\mathbf{1}^{\text {st }}$ Network: Temperature-dependent 8-chain model [13, 14, power-law flow rate, hydrostatic pressure dependence, power-law temperature dependence

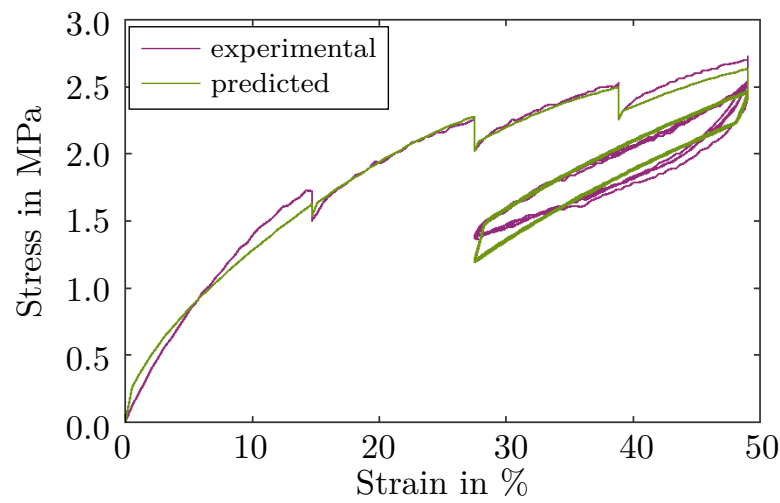

FiguRE 6. Experimental and predicted stress-strain diagram.

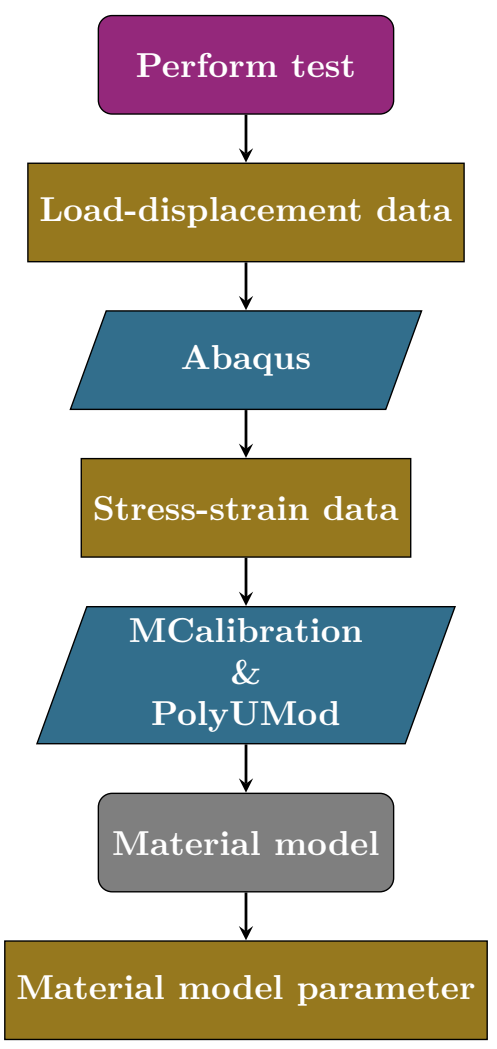

FIGURE 7. Workflow for the parallel network material model (PNMM).

$2^{\text {nd }}$ Network: Temperature-dependent 8-chain model, shear modulus evolution with plastic strain, power-law flow rate, hydrostatic pressure dependence, power-law temperature dependence

$3^{\text {rd }}$ Network: 8-chain model with first order $\mathrm{I}_{2}$ (second invariant of deformation tensor) dependence.

With a simulation, the stress-strain data (Figure 5 was calculated, which is imported and processed in MCalibration. The material parameters are calculated analytically by comparing the predicted results to the experimental ones and updating these parameters until the results fit. In that way, the material parameters are generated (Table 1) and the experimental as well as predicted strain-stress curves are shown in Figure 6 . 


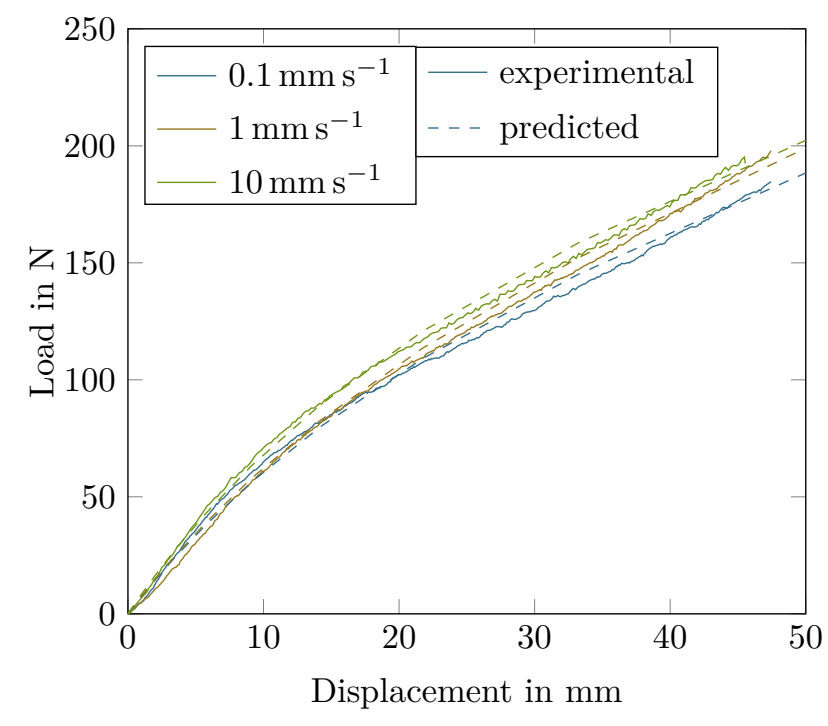

FIGURE 8. Experimental and predicted forcedisplacement diagram with the Mooney-Rivlin model.

\begin{tabular}{|c|c|c|c|}
\hline $\begin{array}{c}\text { Velocity } \\
{\left[\mathrm{mm} \mathrm{s}^{-1}\right]}\end{array}$ & $\begin{array}{c}\mathbf{C}_{\mathbf{1 0}} \\
{[\mathrm{MPa}]}\end{array}$ & $\begin{array}{c}\mathrm{C}_{\mathbf{0 1}} \\
{[\mathrm{MPa}]}\end{array}$ & $\mathbf{D}$ \\
\hline $\mathbf{0 . 1}$ & 0.5849 & 0.0856 & 0 \\
\hline $\mathbf{1}$ & 0.5924 & 0.1016 & 0 \\
\hline $\mathbf{1 0}$ & 0.5979 & 0.1506 & 0 \\
\hline
\end{tabular}

TABle 2. Parameter table of the received MooneyRivlin model-parameters.

\subsection{Finite element updating (FEU)}

The workflow for the FEU is shown in Figure 10 Tests with velocities of $0.1 \mathrm{~mm} \mathrm{~s}^{-1}, 1 \mathrm{~mm} \mathrm{~s}^{-1}$ and $10 \mathrm{~mm} \mathrm{~s}^{-1}$ (Figure 1B) were performed and the load-displacement data were recorded (Figure 8 , solid lines). These data were imported separately to MATLAB [15] and a custom-made FEU-script is executed. This prepares the input file for Abaqus automatically, executes the solver, performs a numerical simulation and extracts the simulated results. It compares the simulated (predicted) results to the experimental ones, updates the material parameters in the input file and repeats that procedure until the load-displacement curve fit within a defined tolerance. The gained material parameters are liste in Table 2 and the compared load-displacement data are shown in Figure 8 Furthermore, the evolution of the parameters $C_{10}$ and $C_{01}$ are visualized in Figure 9

\section{Results And Discussion}

In order to analyze the difference of the three terms of accuracy and experimental effort, the advantages as well as the disadvantages are summarized individually.

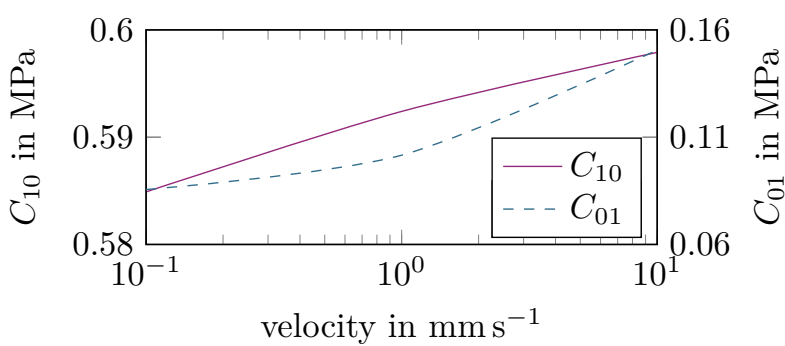

Figure 9. Evolution of $C_{10}$ and $C_{01}$ over the velocity.

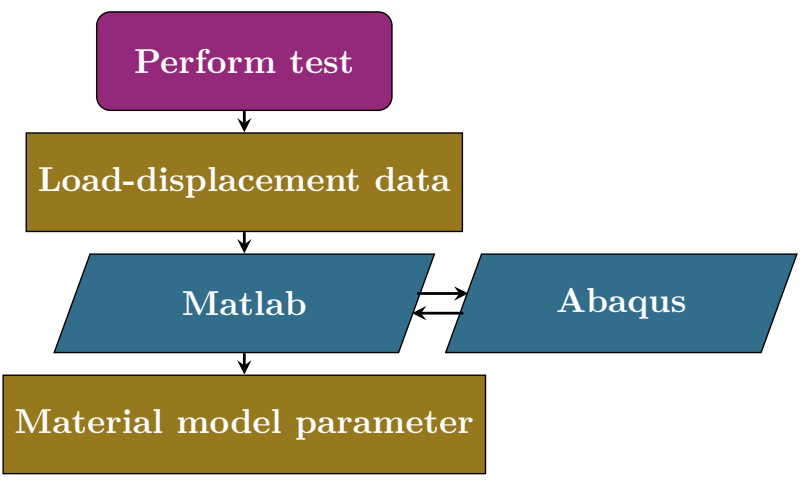

Figure 10. Workflow for the finite element updating (FEU).

\section{- Virtual fields method (VFM)}

The stress-strain data were calculated by VFM, in which the actual full-field strain data is considered. This full-field data includes some information about the sliding of the clamping system, elastic extension of the machine due to the force and some other small effects, which cause deviation between the measured and applied length. Therefore, these effects can be taken into account and excluded. Furthermore, more than one material parameter can be analyzed by generating inhomogeneous strain fields (different loading states) in one test and specimen. However, there are difficulties in finding the right equations for the virtual strain field of each loading condition and its specific (geometric) constraints to receive the right parameters and DIC data is needed, which cause higher effort for acquisition and a huge amount of computational power.

\section{- Parallel network material model (PNMM)}

The result of PNMM are the nonlinear material model parameter which include here (but is not limited to) viscoelastic, relaxation and cyclic behaviour, which gives the whole range of velocity dependence at a certain temperature and loading configuration with one test. Stress-strain data must be evaluated by a simulation and the analytical calculation of the material model parameters is time consuming. Furthermore, different parameter combinations of the same material model and the same test data can be received by choosing different initial parameters. Therefore, the results have to be examined carefully. The selection of the material model is important for the characteristics and the accuracy. 


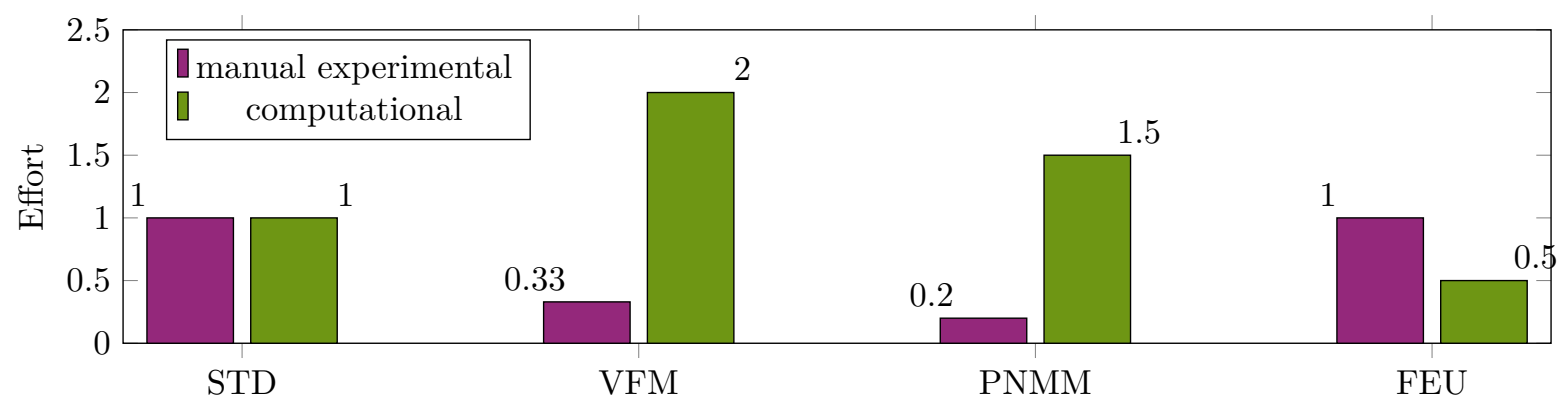

Figure 11. Manual experimental and computational effort of virtual fields method (VMF), parallel network material model (PNMM) and finite element updating (FEU) normalized to the standard method (STD).

\section{- Finite element updating (FEU)}

The result of FEU are the nonlinear material model parameters. Therefore, results from specimen, as well as component tests can be taken to create a simulation. To receive the appropriate results, it is necessary to create a detailed simulation with the proper boundary conditions. Furthermore, the selection of the material model is essential for the results. However, there are different parameter combinations for the same material model and simulation just by choosing different initial parameters. Careful analyses of the results at various loading rates are required.

The comparison of the manual and computational experimental effort of the three methods VFM, PNMM and FEU, normalized to the standard method (STD) (cf. section 1) is shown in Figure 11. The manual experimental effort for the standard test consists of three test procedures (uniaxial, pure shear, equibiaxial), five temperatures and five test velocities, which leads to 75 tests (section 1). Through the inhomogeneous strainfield of the VFM, the three test procedures can be minimized to one, which gives 25 tests, however, because of DIC, the computational effort is more than doubled compared to STD. For the PNMM, the whole range of velocity data for a certain temperature is included in one test, this cause 15 tests altogether, but the computational effort is by $50 \%$ greater than STD. This is caused by the desired stress-strain data and the analytical calculations. The FEU has no benefit on the reduction of the number of tests, nevertheless, the computational effort for small FEM-simulations can be minimized, as the force-displacement data is selected directly.

\section{ACKNOWLEDGEMENTS}

The research for this paper was performed within the framework of FFG 7th call of "Produktion der Zukunft" (Project Number: 848620).

\section{REFERENCES}

[1] L. Treloar. The elasticity and related properties of rubbers. Reports on progress in physics 36(7):755, 1973.

[2] U. D. Çakmak, Z. Major. Experimental

Thermomechanical Analysis of Elastomers Under Uni- and Biaxial Tensile Stress State. Experimental Mechanics 54(4):653-663, 2014.

[3] U. D. Çakmak, I. Kallaí, Z. Major. Temperature dependent bulge test for elastomers. Mechanics Research Communications 60:27-32, 2014.

[4] E. Leiss-Holzinger, U. D. Çakmak, B. Heise, et al. Evaluation of structural change and local strain distribution in polymers comparatively imaged by FFSA and OCT techniques. Express Polym Lett 6:249-256, 2012.

[5] N. W. Tschoegl, W. G. Knauss, I. Emri. The Effect of Temperature and Pressure on the Mechanical Properties of Thermo- and/or Piezorheologically Simple Polymeric Materials in Thermodynamic Equilibrium-A Critical Review. Mechanics of Time-Dependent Materials 6(1):53-99, 2002.

[6] U. D. Çakmak. Experimental Studies on Time-Temperature-Dependent Bulk and Surface Behavior of Soft Composite Materials. Ph.D. thesis, Johannes Kepler University, 2014.

[7] A. Grambow. Bestimmung der Materialparameter gefüllter Elastomere in Abhängigkeit von Zeit, Temperatur und Beanspruchungszustand. Ph.D. thesis, Bibliothek der RWTH Aachen, 2002.

[8] Ncorr. Ncorr. http://www.ncorr.com, 2016.

[9] F. Pierron, M. Grédiac. The Virtual Fields Method: Extracting Constitutive Mechanical Parameters from Full-field Deformation Measurements. Springer Science \& Business Media, 2012.

[10] J. Bergström. PolyUMod User's Manual. Veryst Engineering, LLC, Needham, MA 2009.

[11] Hibbett, Karlsson, Sorensen. ABAQUS/standard: User's Manual, vol. 1. Hibbitt, Karlsson \& Sorensen, 1998.

[12] J. Bergström, J. Bischoff. An Advanced Thermomechanical Constitutive Model for UHMWPE. The International Journal of Structural Changes in Solids 2(1):31-39, 2010.

[13] E. M. Arruda, M. C. Boyce. A Three-Dimensional Constitutive Model for the Large Stretch Behavior of Rubber Elastic Materials. Journal of the Mechanics and Physics of Solids 41(2):389-412, 1993.

[14] J. Bergström, M. Boyce. Large Strain Time-Dependent Behavior of Filled Elastomers. Mechanics of materials 32(11):627-644, 2000.

[15] C. Moler, et al. MATLAB User's Guide. University of New Mexico, 1982. 